Available online at GSC Online Press Directory

GSC Biological and Pharmaceutical Sciences

e-ISSN: 2581-3250, CODEN (USA): GBPSC2

Journal homepage: https://www.gsconlinepress.com/journals/gscbps

(RESEARCH ARTICLE)

\title{
Environmental control of malaria: Can Citrus sinensis peel be a potent larvicide for household vector control?
}

\author{
Ukpong Iniodu George * \\ Department of Animal and Environmental Biology, Cross River University of Technology, Calabar, Nigeria.
}

Publication history: Received on 04 December 2019; revised on 13 December 2019; accepted on 17 December 2019

Article DOI: https://doi.org/10.30574/gscbps.2019.9.3.0236

\begin{abstract}
The quest for alternatives to chemical-based insecticides has raised inquiries on various plant products for their potential efficacy in killing or repelling mosquitoes and eco-friendliness. However, as research inquiries build up, populations in endemic areas are still vulnerable to active malaria transmission maintained by competent vectors. Practical solutions deriving from research inferences should constantly be delivered by easy and affordable means to vulnerable populations. This study assessed the larvicidal efficacy of aqueous extract of Citrus sinensis, to determine the potentiality of developing a cheap, effective, and eco-friendly product from a local plant for environmental control of the malaria mosquito. Weighed quantities, $50 \mathrm{~g}, 100 \mathrm{~g}, 150 \mathrm{~g}$ and $200 \mathrm{~g}$ of fresh orange fruit (Citrus sinensis) peels were respectively subjected to low heating in $100 \mathrm{ml}$ of distilled water for 30 minutes and allowed to soak for 24 hours, to obtain stock aqueous extract of $0.5 \mathrm{~g} / \mathrm{ml}, 1.0 \mathrm{~g} / \mathrm{ml}, 1.5 \mathrm{~g} / \mathrm{ml}$ and $2.0 \mathrm{~g} / \mathrm{ml}$ concentrations, respectively. Thirty 4 th instar larvae of Anopheles species maintained in $100 \mathrm{ml}$ of natural breeding source water were treated with the extracts. Twenty four (24)-hour exposure produced concentration-dependent mortality of mosquito larvae ( $<<0.05$ ). Percentage mortality ranged between $65.57 \%$ and $100 \%$, with $2.0 \mathrm{~g} / \mathrm{ml}$ concentration at all test volumes causing $100 \%$ mortality. The results suggest that aqueous extract of $\mathrm{C}$. sinensis could be a potent eco-friendly mosquito control agent. This study documents the feasibility and effectiveness of a simple extraction method applicable at home for local and massive community-based malaria vector control. However, field trials of this simple procedure would ascertain the extent of achievable success.
\end{abstract}

Keywords: Malaria; Mosquito; Citrus sinensis; Larvicide; Vector control

\section{Introduction}

Although malaria transmission by the Anopheles mosquito was finally established as early as 1898 [1], the first global effort against the disease directed at the vector did not come until 1955 when the World Health Organisation (WHO) initiated the Global Eradication of Malaria Program. The theory of the eradication programme was based on application of residual insecticides on a total coverage basis over time to stop transmission, while chemotherapy was to be a safeguard to eliminate actual or potential foci of infection to ensure success of the insecticidal campaign, [2]. However the global campaign was stopped in 1969 when it became clear that global eradication was not possible in the foreseeable future. The campaign needed to indeed have a global coverage to be meaningful, and not restricted to the main targets of Americas, Asia, and endemic areas of Europe [3]. With the declaration of malaria control a global priority via resolution WHA 42.30 (1989) by the World Health Assembly, the subsequent World Declaration on the Control of Malaria in 1992 gave rise to the Global Malaria Control Strategy, to focus on the following elements: Early diagnosis and prompt treatment of cases; chemoprophylaxis in high risk groups; reduction of man-vector contact; vector control in appropriate epidemiological settings; prediction, prevention, prompt and effective management of epidemics; monitoring and evaluation; information, education and communication; Research [4][5][6].

\footnotetext{
${ }^{*}$ Corresponding author

E-mail address: drgeorge@crutech.edu.ng
}

Copyright (C) 2019 Author(s) retain the copyright of this article. This article is published under the terms of the Creative Commons Attribution Liscense 4.0 
Vector control is therefore a virile approach in the malaria management process. The various vector control options available include indoor residual spraying, personal protection measures, biological control, (larviciding), environmental management and space spraying. Some of these methods may not provide desired control impact on their own in all situations. This necessitates the integrated use of control methods. As important as mosquito control is, the best approach to it has been an issue for consideration. Like in the earliest global eradication effort of residual insecticide campaign [7] the effectiveness of insecticidal methods is strongly held [8] based on the concept of the underlying benefit of reducing mosquito longevity, rather than attempts to reduce mosquito density, in order to limit transmission potential. This concept supports systematic house spraying as an effort to destroy the actual vectors which are the infected mosquitoes host-seeking indoors [9].

The main malaria prevention option since the last decade has been vector control by use of insecticide-treated mosquito nets (ITN) and indoor residual spraying (IRS). However, according to the World Health Organisation, while ITN coverage rose from $29 \%$ in 2010 to about $50 \%$ in 2017, IRS protection dwindled from $5 \%$ to $3 \%$ within the period [World malaria report 2018. www.who.int/malaria/publications/world-malaria-report-2018/en/, last accessed on 23/04/2019]. Current indicators show no significant progress in reducing global malaria cases between 2015 and 2017 [WHO Fact sheet on Malaria. www.who.int/news-room/fact-sheets/detai/malaria, last accessed on 23/04/2019].

The current fact sheet implies that there are challenges with the ITN and IRS approach to vector control in malaria management. Outdoor transmission and the rising levels of insecticide resistance are among the factors threatening the success of this approach [10]. The current decrease in IRS protection is said to occur as countries seek alternatives to the affordable pyrethroid insecticides to which the mosquito vector has developed resistance [WHO Fact sheet on Malaria. www.who.int/news-room/fact-sheets/detai/malaria, last accessed on 23/04/2019]. This arouses the need for cheaper and effective alternative insecticides.

The quest for alternatives to chemical-based insecticides has raised inquiries on various plant products for their potential efficacy in killing or repelling mosquitoes [11]. Recent studies have been beamed on local products that could be candidates for environment-friendly insecticides; including larvicidal efficacies [12][13][14][15][16][17][18]. Insecticidal activity of peel extract of Citrus species has been extensively documented [19][20][21]. This property is owed to their content of secondary metabolites known to have insecticidal effect on various arthropods [22]. Saponins in the orange peel are known to have larvicidal efficacy against mosquitoes [23][24]. While many studies have tested the insecticidal property of essential oils, some have also applied crude aqueous extracts of plant products [25][26].

As research inquiries build up in this regard, the practical application of inferences is paramount. Populations in endemic areas are still vulnerable to active malaria transmission maintained by competent vectors. Practical solutions deriving from research inferences should constantly be delivered by easy and affordable means to vulnerable populations. Is it possible to adapt simple procedures and harness the larvicidal activity of a plant product for vector control at the local (household) level? This study was set to assess the larvicidal efficacy of aqueous extract of Citrus sinensis, to determine the potentiality of developing a cheap, effective, and eco-friendly product from a local plant for environmental control of the malaria mosquito.

\section{Methodology}

\subsection{Preparation of aqueous extract}

Fresh orange fruits (Citrus sinensis) purchased from Watt Market, Calabar, were washed in distilled water and peeled with a knife. $50 \mathrm{~g}, 100 \mathrm{~g}, 150 \mathrm{~g}$ and $200 \mathrm{~g}$ of orange peels were respectively subjected to low heating in $100 \mathrm{ml}$ of distilled water for 30 minutes and allowed to soak for 24 hours. The preparations were filtered through a $4 \mathrm{~mm}$ sieve to obtain stock aqueous extract of $0.5 \mathrm{~g} / \mathrm{ml}, 1.0 \mathrm{~g} / \mathrm{ml}, 1.5 \mathrm{~g} / \mathrm{ml}$ and $2.0 \mathrm{~g} / \mathrm{ml}$ concentrations, respectively; from which two test volumes, $5 \mathrm{ml}$ and $10 \mathrm{ml}$, of each were obtained for larvicidal activity test.

\subsection{Collection of mosquito larvae}

Mosquito larvae were collected from breeding sites in clogged drainage and small pools of water in the surroundings of students' hostels within the campus of the Cross River University of Technology, Calabar. Volumes of the pools harbouring larvae were scooped directly to capture Larvae in their natural breeding medium in order to maintain the natural environmental characteristics that support and sustain vector breeding while the test lasted. Larvae identified as 4th instar of Anopheles species were used for the study. 


\subsection{Larvicidal activity test}

Thirty (30) larvae were maintained in $100 \mathrm{ml}$ of breeding source water held in separate beakers; and $5 \mathrm{ml}$ and $10 \mathrm{ml}$ of each of the four concentrations of the aqueous extract, $0.5 \mathrm{~g} / \mathrm{ml}, 1.0 \mathrm{~g} / \mathrm{ml}, 1.5 \mathrm{~g} / \mathrm{ml}$ and $2.0 \mathrm{~g} / \mathrm{ml}$, were added to the respective beakers using spray bottle. Larvicidal activity of extract was monitored over a 24-hour period. The procedures were repeated twice with freshly collected larvae; hence mean values were derived from three test sets. The test control consisted of larvae suspended in breeding source water as described above without treatment with $C$. sinensis extract.

\subsection{Data analysis}

Observed larvicidal effect was determined as percentage mortality (\% Mortality) calculated using Abbott's formula as Number of larvae dead/Number of larvae taken x 100. Mortality rate and extract concentration were analysed using ttest at $\mathrm{p}<0.05$. The mean concentration and mean mortality rate were compared using the SPSS.

\section{Results}

Twenty four (24)-hour exposure of mosquito larvae to aqueous extract of $C$. sinensis produced concentrationdependent mortality of the former, $(\mathrm{p}<0.05)$. Percentage mortality ranged between $65.57 \%$ and $100 \%$. Zero larvicidal activity was recorded with $0.5 \mathrm{~g} / \mathrm{ml}$ and $1.0 \mathrm{~g} / \mathrm{ml}$ concentrations at all test volumes of the aqueous extract. While concentrations of $1.5 \mathrm{~g} / \mathrm{ml}$ inflicted volume-dependent mortality with mean mortality of $65.57 \%$ and $78.87 \%$ for $5 \mathrm{ml}$ and $10 \mathrm{ml}$ volumes, respectively, $2.0 \mathrm{~g} / \mathrm{ml}$ concentration at both test volumes caused death of all test larvae $(100 \%$ mortality), (Table 1 and Figure 1). The test control showed $4^{\text {th }}$ instar larvae active after 24 hours.

Table 1 Larvicidal activity of aqueous extract of Citrus sinensis peel on mosquito larvae

\begin{tabular}{lll}
\hline Test Volume (m) & Extract Concentration $(\mathrm{g} / \mathbf{m l})$ & Mean mortality $(\%)$ \\
\hline 5.0 & 0.5 & 0 \\
\cline { 2 - 3 } & 1.0 & 0 \\
& 1.5 & 65.57 \\
& 2.0 & 100 \\
\hline 10 & 0.5 & 0 \\
\cline { 2 - 3 } & 1.0 & 0 \\
& 1.5 & 78.87 \\
& 2.0 & 100 \\
Control 5ml, 10ml & 0 & 0 \\
\hline
\end{tabular}

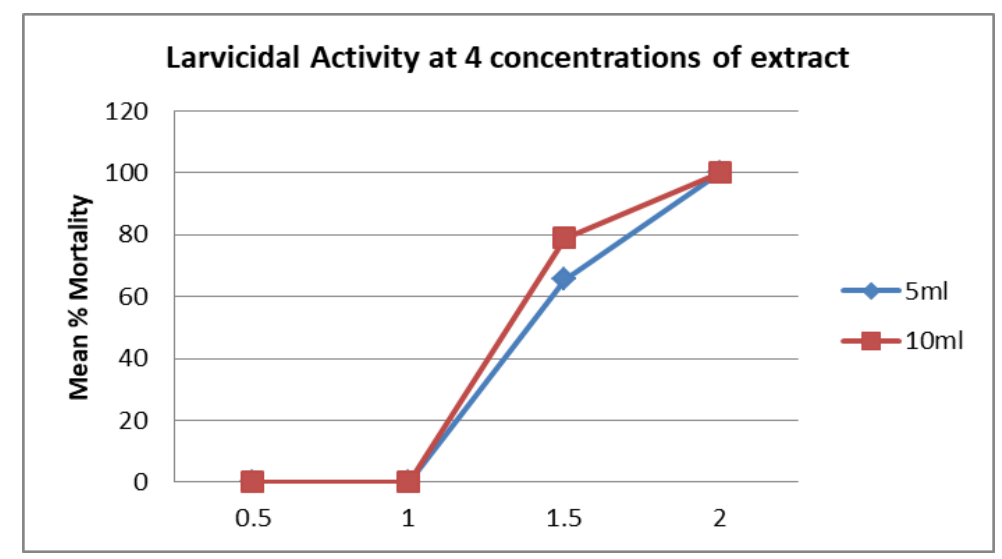

Figure 1 Larvicidal activity of aqueous extract at various concentrations and test volumes 


\section{Discussion}

Investigation of insecticidal activity of plant extracts is not novel; however, most studies have focused on the activity of oil extract of choice plants on adult and larval mosquitoes. The focus of this study was on testing the potentialities of aqueous extract of a common and readily available plant product as larvicidal agent against malaria mosquito as a contribution to the on-going quest for eco-friendly vector control measures for the tropical disease. Indeed, testing the larvicidal activity of aqueous extract of Citrus sinensis is not exclusive, either; what is significant is that this study employed a bioassay that maintained the mosquito larvae in their natural environment in order to limit or completely eliminate external influence on the ecology and microenvironment of the developing insect. This was necessary since the aim of the investigation was to determine the candidacy of the test plant product for environmental (outdoor) control of the vector. Also, a simple extraction method of obtaining the crude aqueous extract that could be performed at homes was adopted. Again, this was strategic since the study also considered the possibilities of utilizing the benefits of orange peel extract at the household level for local control of mosquito population around homes. This also informed the limited test duration of 24 hours, to observe if the test product could exhibit its efficacy before the $4^{\text {th }}$ instar larva, which is the last larval stage, could pupate.

This study has identified concentration-dependent potency $(\mathrm{p}<0.05)$ of aqueous extract of the peel of sweet orange, Citrus sinensis, against the larvae of Anopheles mosquito. This corroborates similar reports of concentration and timedependent larvicidal activity of $2 \%, 3 \%$ and $4 \%$ of aqueous extract of $C$. sinensis peel and leaf on Culex quinquefasciatus [25]. Studies with ethanolic extracts [19] and extractions using other solvents [27][28] have also documented such lethal effect of $C$. sinensis peel on various species of mosquitoes. Reports of these and similar studies are in agreement that given tested larvicidal activity, $C$. sinensis can be a source of eco-friendly mosquito control product.

The aqueous extract at $2 \%$ concentration could immobilize and kill the $4^{\text {th }}$ instar larvae within 24 hours. This larvicidal action, known to be exerted by secondary metabolites [22], especially Saponins in the orange peel [23][24], truncates the life cycle of the insect at the larval stage before it could pupate. This indicates that proliferation of mosquitoes at desired locations can be achieved with the application of the orange peel product; and accordingly, this would not only check rising vector population, active transmission could readily be hindered in an area, bearing in mind the obvious that it is only adult mosquitoes that bite and transmit the infection.

This study corroborates previous findings and views; and having demonstrated the feasibility and effectiveness of a simple extraction method, which is possible at home, it thus documents the applicability of aqueous extract of $C$ sinensis for spot and massive community-based vector control against malaria.

\section{Conclusion}

This study has shown that malaria control using aqueous extract of $C$ sinensis can be easily carried out in individual homes to protect families from malaria attack. It does not exert any significant financial burden on the family, since the functional item (the peel) is waste from a fruit, which is indeed readily available in most communities in the tropical region where malaria transmission is effective due to abundance of the efficient vector. Availability of ecofriendly alternative would deter people, especially at the community level from the use of chemical-based insecticides with significant environmental implications. However, field trials of this simple procedure would ascertain the extent of success achievable; and this is recommended.

\section{Compliance with ethical standards}

\section{Acknowledgments}

The contribution of the entomologist in the department of Animal and Environmental Biology, Cross River University of Technology, Calabar, by identifying Anopheles mosquito larvae is greatly acknowledged.

\section{Disclosure of conflict of interest}

There is no conflict of interest. 


\section{References}

[1] Desowitz RS. (1991). The Malaria capers (More tales of parasites and people, research and reality). W. W. Norton and Company, New York.

[2] Litsios S. (2000). Criticism of WHO's Revised Malaria eradication strategy. Parassitologia, 42, 167-172.

[3] Baird JK. (2000). Resurgent malaria at the Millenium: Control strategies in crisis. Drugs, 59, 719-743.

[4] WHO (1993a). A global strategy for malaria control. World Health Organisation, Geneva, Switzerland.

[5] WHO (1993b). Implementation of the Global Malaria Control Strategy. World Health Organisation, Geneva, Switzerland.

[6] WHO (1995). Vector control for malaria and other mosquito-borne disease. WHO Technical Report Series 857. World Health Organisation, Geneva, Switzerland.

[7] WHO (1957). Malaria: Sixth report of the expert committee. Technical Report Series, No. 123. World Health Organisation, Geneva, Switzerland.

[8] Udonsi JK. (1999). Parasites and parasitic diseases: A textbook of general and medical parasitology in tropical Africa. Josany press, Portharcourt, Nigeria, 275.

[9] White GB. (1999). Malaria prevention by vector control: Effectiveness of insecticidal methods. Parassitologia, 41, 385-387.

[10] Benelli G and Beier JC. (2017). Current vector control challenges in the fight against malaria. Acta Tropica, 174, 91-96.

[11] Maia MF and Moore SJ. (2011). Plant-based insect repellents: a review of their efficacy, development and testing. Malar. J., 10(1), S11.

[12] Vinayagam A, Senthilkumar N and Umamaheswari A. (2008). Larvicidal activity of some medicinal plants extracts against malaria vector Anopheles stephensi. Research Journal of Parasitology, 3(2), 50-58.

[13] Kamaraj C, Rahuman AA, Mahapatra A, Bagavan A and Elango G. (2010). Insecticidal and larvicidal activities of medicinal plant extracts against mosquitoes. Parasitol Res, 107(6), 1337-49.

[14] Maragathavalli S, Brindha S, Kaviyarasi NS, Annadurai B and Gangwar SK. (2012). Mosquitoes larvicidal activity of leaf extract of Neem (Azaradichta indica). International Journal of Advanced Biological Research, 2(1), 138142.

[15] Ukpong IG, Etta HE and Eshuong EE. (2016). Studies on mosquito repellent activity of Cymbopogon citratus (Lemon Grass) using human volunteers. International Journal of Research-Granthaalayah, 4(12), 41-47.

[16] Hannah EE, Ukpong IG, Iboh C and Nshar ME (2016). Preliminary investigations of the insecticidal effect of Ocimum gratissimum on adult Anopheles mosquitoes. .International Journal of Health and Pharmaceutical Research, 2(1), 66-71.

[17] Agure HIJ, Obiora M, Iorgema CU, Elijah BB, Dawuda BM and Agbo JO. (2019). Bioassay of synthetic larvicide and the Neem seed oil on mosquito larvae: A serach for ecofriendly larvicide. Book of Abstracts, Parasitology and public health society of Nigeria, 43rd Scientific conference, 10-13 September 2019, Portharcourt, Nigeria.

[18] Umohata IA and Ubulom PME. (2019). Potency of Ethanol extract and fractions of the leaf of Annona muricata against Aedes aegypti larvae. Book of Abstracts, Parasitology and public health society of Nigeria, 43rd Scientific conference, 10-13 September 2019, Portharcourt, Nigeria.

[19] Murugan K, Kumar PM, Kovendan K, Amerasan D, Subrmaniam J and Hwang J. (2012). Larvicidal, pupicidal, repellent and adulticidal activity of Citrus sinensis orange peel extract against Anopheles stephensi, Aedes aegypti and Culex quinque fasciatus (Diptera: Culicidae). Parasitology Research.

[20] Yunis MI. (2014). Effect of Orange Peel (Citrus sinensis) (L) extrcts and powder on confused flour beetle Tribolum confusum (Coleoptera: Teneberionidae). Iraqi Journal of Science, 55(3B), 1164-1169.

[21] Simon OIA and Akeju AV. (2011). Laboratory evaluation of extract from peels and seeds of some citrus species against Anopheles mosquitoes (Diptera: Culicidae). International Journal of Mosquitoe Research, 4(5), 48-54.

[22] Service MW. (1983).Management of vectors. In: Youdeowei A and Service MW (Eds), Pest and vectors management in Tropics, Longman, English language book society, London, 265-280. 
[23] Bagavan A, Rahuman AA, Kamaraj C and Geetha K. (2008). Larvicidal activity of saponins from Achyranthes aspera against aedes aegypti and Culex quinquefasciatus (Diptera: Culicidae). Parasitology Research, 103(1), 223-229.

[24] Milind P and Dev C. (2012). Orange: Range of benefits. Int. Res. J. Pharm., 3(7), 59-63.

[25] Sattar M, Iqbal MN, Ashraf, A, Ali S, Shahzad MI, Alam S, Ali T and Sheikh R. (2016). Larvicidal efficacy of Citrus sinensis extracts against Culex quinquefasciatus. PSM Microbiology, 01(2), 56-61.

[26] Azare BA, Paul DE, Tanimowo EO, Paiko H and Lawal A. (2019). Larvicidal control of mosquito vector using total crude water extracts of Moringa oleifera (Moringa) and Azadirachta indica (Neem). Book of Abstracts, Parasitology and public health society of Nigeria, 43rd Scientific conference, 10-13 September 2019, Portharcourt, Nigeria.

[27] Warikoo R, Ray A, Sandhu JK, Samal R, Wahab N and Kumar S. (2012). Larvicidal and irritant activities of Hexane leaf extracts of Citrus sinensis against dengue vector Aedes aegypti L. Asian Pacific Journal of Tropical Biomedicine, 2(2), 152-155.

[28] Bilal H, Akram, W, Hassan, SA and Din S. (2017). Citus seed oils efficacy against larvae of Aedes aegypti. J. Arthropod Borne Dis., 11(3), 427-432.

\section{How to cite this article}

Ukpong IG. (2019). Environmental control of malaria: Can Citrus sinensis peel be a potent larvicide for household vector control? GSC Biological and Pharmaceutical Sciences, 9(3), 85-90. 